\title{
Gradual Aeration at Birth Is More Lung Protective Than a Sustained Inflation in Preterm Lambs
}

\author{
David G. Tingay $y^{1,2,3,4}$, Prue M. Pereira-Fantini ${ }^{1,4}$, Regina Oakley ${ }^{1}$, Karen E. McCall ${ }^{1}$, Elizabeth J. Perkins ${ }^{1,2}$, \\ Martijn Miedema ${ }^{1,5}$, Magdy Sourial ${ }^{1}$, Jessica Thomson ${ }^{1}$, Andreas Waldmann ${ }^{6}$, Raffaele L. Dellaca ${ }^{7}$, Peter G. Davis ${ }^{1,3,8}$, \\ and Peter A. Dargaville $1,9,10$
}

${ }^{1}$ Neonatal Research, Murdoch Childrens Research Institute, Parkville, Victoria, Australia; ${ }^{2}$ Neonatology, The Royal Children's Hospital, Parkville, Victoria, Australia; ${ }^{3}$ Neonatal Research, The Royal Women's Hospital, Parkville, Victoria, Australia; ${ }^{4}$ Department of Paediatrics and ${ }^{8}$ Department of Obstetrics and Gynaecology, University of Melbourne, Melbourne, Victoria, Australia; ${ }^{5}$ Neonatology, Amsterdam University Medical Centre, University of Amsterdam, Amsterdam, the Netherlands; ${ }^{6}$ Swisstom AG, Landquart, Switzerland; 'Dipartimento di Elettronica, Informazione e Ingegneria Biomedica, Politecnico di Milano University, Milan, Italy; ${ }^{9}$ Neonatal and Paediatric Intensive Care Unit, Royal Hobart Hospital, Hobart, Tasmania, Australia; and ${ }^{10}$ Menzies Institute for Medical Research, University of Tasmania, Hobart, Tasmania, Australia

ORCID IDs: 0000-0003-1522-4691 (D.G.T.); 0000-0002-3672-4591 (R.L.D.).

\section{Abstract}

Rationale: The preterm lung is susceptible to injury during transition to air breathing at birth. It remains unclear whether rapid or gradual lung aeration at birth causes less lung injury.

Objectives: To examine the effect of gradual and rapid aeration at birth on: 1) the spatiotemporal volume conditions of the lung; and 2) resultant regional lung injury.

Methods: Preterm lambs (125 $\pm 1 \mathrm{~d}$ gestation) were randomized at birth to receive: 1 ) tidal ventilation without an intentional recruitment (no-recruitment maneuver [No-RM]; $n=19$ ); 2) sustained inflation (SI) until full aeration $(n=26)$; or 3$)$ tidal ventilation with an initial escalating/de-escalating (dynamic) positive end-expiratory pressure (DynPEEP; $n=26$ ). Ventilation thereafter continued for 90 minutes at standardized settings, including PEEP of $8 \mathrm{~cm} \mathrm{H} \mathrm{H}_{2} \mathrm{O}$. Lung mechanics and regional aeration and ventilation (electrical impedance tomography) were measured throughout and correlated with histological and gene markers of early lung injury.
Measurements and Main Results: DynPEEP significantly improved dynamic compliance $(P<0.0001)$. An SI, but not DynPEEP or No-RM, resulted in preferential nondependent lung aeration that became less uniform with time $(P=0.0006)$. The nondependent lung was preferential ventilated by 5 minutes in all groups, with ventilation only becoming uniform with time in the No-RM and DynPEEP groups. All strategies generated similar nondependent lung injury patterns. Only an SI caused greater upregulation of dependent lung gene markers compared with unventilated fetal controls $(P<0.05)$.

Conclusions: Rapidly aerating the preterm lung at birth creates heterogeneous volume states, producing distinct regional injury patterns that affect subsequent tidal ventilation. Gradual aeration with tidal ventilation and PEEP produced the least lung injury.

Keywords: preterm; respiratory transition; lung injury; sustained inflation; lung mechanics

(Received in original form July 29, 2018; accepted in final form February 7, 2019)

Supported by a National Health and Medical Research Council Project Grant (1009287) and the Victorian Government Operational Infrastructure Support Program (Melbourne, Victoria, Australia), a National Health and Medical Research Council Clinical Career Development Fellowship (1053889; D.G.T.), and a National Health and Medical Research Council Program Grant (606789) and a National Health and Medical Research Council Practitioner Fellowship (556600; P.G.D.). Chiesi Farmaceutici S.p.A. provided the Curosurf used in this study as part of an unrestricted grant (D.G.T.) at the Murdoch Childrens Research Institute.

Chiesi Farmaceutici and Swisstom had no involvement in study design, implementation, analysis, interpretation, or reporting.

Author Contributions: D.G.T., R.L.D., P.G.D., and P.A.D. developed the concept, designed the experiment, and interpreted the data; D.G.T., P.M.P.-F., K.E.M., E.J.P., M.M., and M.S. were involved in all lamb experimental work; D.G.T. supervised all aspects of the study and subsequent data analysis; P.M.P.-F. and R.O. performed the lung injury analysis; A.W. developed the lamb-specific electrical impedance tomography (EIT) analysis software; D.G.T., K.E.M., J.T., and A.W. performed the EIT analysis; all authors participated in data interpretation under the supervision of D.G.T., R.L.D., P.G.D., and P.A.D.; and D.G.T. wrote the first draft and all authors contributed to redrafting the manuscript.

Correspondence and requests for reprints should be addressed to David G. Tingay, M.B. B.S., D.C.H., F.R.A.C.P., Ph.D., Neonatal Research, Murdoch Childrens Research Institute, Royal Children's Hospital, Flemington Road, Parkville, 3052 VIC, Australia. E-mail: david.tingay@rch.org.au.

This article has an online supplement, which is accessible from this issue's table of contents at www.atsjournals.org.

Am J Respir Crit Care Med Vol 200, Iss 5, pp 608-616, Sep 1, 2019

Copyright $\odot 2019$ by the American Thoracic Society

Originally Published in Press as DOI: 10.1164/rccm.201807-1397OC on February 7, 2019

Internet address: www.atsjournals.org 


\section{At a Glance Commentary}

\section{Scientific Knowledge on the}

Subject: From the first inflations at birth, the preterm lung is particularly prone to injury. It has been proposed that emulating the respiratory transition of term infants by rapidly aerating the lung using an initial sustained inflation (SI) may be beneficial in preterm infants. Clinical and preclinical studies comparing SI to gradual aeration of the lung using tidal inflations and positive end-expiratory pressure (PEEP) have been inconclusive. An understanding of the impact of aeration strategy on regional aeration, ventilation, and resultant lung injury is lacking.

\section{What This Study Adds to the}

Field: Gradual aeration at birth results in more uniform aeration and ventilation and better lung mechanics than an SI if supported with sufficient end-expiratory pressure. An SI preferentially aerated the nondependent lung at birth, and led to inhomogeneity of ventilation and aeration and emergence of early injury markers in the dependent lung not seen with gradual aeration. The existing clinical focus on rapid and complete lung aeration as the first priority at birth may be causing unintentional harm. Gradual aeration during tidal ventilation with sufficient PEEP is more protective.

The initial respiratory transition to air breathing after birth is a complex process of aeration requiring: 1 ) rapid clearance of fetal lung fluid; 2) the establishment of an effective FRC; and 3) initiation and maintenance of tidal ventilation (1-3). Spontaneously breathing infants born at term are highly successful at making this transition, aided by initial high driving pressures and long inspiratory times to overcome the prolonged time constant and high resistance of the fluid-filled respiratory system (4-6), followed by sufficient endexpiratory pressure to prevent fluid influx back into the alveoli (1). Preterm infants, on the other hand, often cannot transition to air breathing independently, and resuscitative assistance, including positive- pressure ventilation (PPV), is required. Furthermore, the developmental stage of the preterm respiratory system at birth predisposes to atelectasis and heterogeneity of ventilation, both known to be associated with lung injury when combined with artificial ventilation (7-10). Delivery room care of the preterm infant is thus increasingly focused on facilitating effective respiratory transition while also minimizing early lung injury (2).

Replicating the long inspiratory times observed in term infants has formed the rationale for a positive-pressure sustained lung inflation (SI) to initially aerate the preterm lung at birth $(1,11)$. In rabbit pups, an initial SI results in quicker aeration than tidal ventilation $(12,13)$, but aeration is similar by 15 minutes of life if sufficient positive end-expiratory pressure (PEEP) is applied (13). These studies were not designed to assess clinical or injury outcomes, and subsequent, longer-duration studies in preterm lambs have been inconclusive $(7,8,14-17)$, with some raising concerns of increased lung injury after SI $(9,18)$. We recently demonstrated in preterm lambs that a transient stepwise escalation then deescalation of PEEP during tidal ventilation at birth improved short-term clinical outcomes compared with an SI optimized to aeration response (7). This approach aims to attain aeration gradually over time during a series of PEEP-supported tidal inflations, rather than rapidly with pressure during the first inflation $(8,16)$.

Preterm lung injury is complex, being multifactorial in causation and, once initiated, unpredictably worsened by ongoing ventilation $(2,19,20)$.

Fundamentally, acute preterm lung injury is an interaction between the immature developmental state of the lung and the volume conditions (such as volutrauma and atelectasis) created at a regional level during respiratory support (21-23). This concept of regional volume-injury interactions has not been investigated in the preterm lung at birth, with existing studies limited to global measures $(9,15,24)$, perhaps explaining the inconclusive outcomes of existing studies. We hypothesize that: 1) the developmental state and regional inhomogeneities of the preterm lung are not conducive to the rapid forced aeration such as occurs during an SI; and 2) gradual aeration using tidal inflations combined with an optimal PEEP strategy is more lung protective than application of an SI.

The specific aims of this study were to determine the independent effect of PEEP, tidal ventilation, and SI at birth on: 1) the volumetric conditions of the lung; and 2) subsequent early development of regional lung injury in the preterm lamb lung. Some of the results of these studies have been previously reported in abstract form (25), and some of the lambs have been used across other studies (26).

\section{Methods}

A detailed methodology can be found in the online supplement. The study was approved by the Murdoch Children's Research Institute Animal Ethics Committee.

\section{Experimental Instrumentation} Lambs (125 $\pm 1 \mathrm{~d}$ preterm) born by Cesarean section to date-mated, betamethasone-treated ewes were instrumented before delivery, including applying a custom-built electrical impedance tomography (EIT) belt around the chest, as described in detail previously $(27,28)$. Spontaneous breathing was suppressed from birth with ketamine and midazolam infusions.

\section{Measurements}

Airway pressure, gas flow, and $\mathrm{V}_{\mathrm{T}}$ at the airway opening (Florian; Acutronic Medical Systems AG) were measured continuously from birth $(200 \mathrm{~Hz})$. Global and regional lung volume changes were acquired by EIT (Pioneer System; Swisstom AG) at 48 scans/s (27-29). Arterial blood analysis was performed at 5 minutes and every 15 minutes from birth.

\section{Recruitment Strategies}

Lambs were randomly assigned before delivery to receive one of the following lung recruitment strategies at birth with $\mathrm{FI}_{\mathrm{O}_{2}}$ held at 0.3 .

Tidal ventilation without a recruitment maneuver group. PPV (SLE5000; SLE Ltd.) in volume-targeted ventilation (VTV) mode at PEEP $8 \mathrm{~cm} \mathrm{H}_{2} \mathrm{O}$, inspiratory time of 0.4 seconds, a rate of 60 inflations per minute, set $\mathrm{V}_{\mathrm{T}}$ of $7 \mathrm{ml} / \mathrm{kg}$, and peak inspiratory pressure (PIP) of $35 \mathrm{~cm} \mathrm{H} \mathrm{H}_{2} \mathrm{O}$.

SI group. SI was maintained at $35 \mathrm{~cm}$ $\mathrm{H}_{2} \mathrm{O}$ until 10 seconds after achievement of a volume plateau on the EIT display (maximum, $180 \mathrm{~s})(7,18,27)$. 
Dynamic stepwise PEEP group.

Commencing at $6 \mathrm{~cm} \mathrm{H}_{2} \mathrm{O}$ during $\mathrm{PPV}+\mathrm{VTV}$ (VT, $7 \mathrm{ml} / \mathrm{kg}$; maximum PIP, $35 \mathrm{~cm} \mathrm{H}_{2} \mathrm{O}$ ), PEEP increased by $2 \mathrm{~cm} \mathrm{H}_{2} \mathrm{O}$ every 10-15 inflations during PPV until no further gain in dynamic compliance (Cdyn; 14-20 $\mathrm{cm} \mathrm{H}_{2} \mathrm{O}$; maximum PEEP), and then similarly decreased to a final PEEP of $8 \mathrm{~cm}$ $\mathrm{H}_{2} \mathrm{O}$ (170-180 s total duration) $(7,8)$.

On completion of the SI or dynamic stepwise PEEP (DynPEEP), PPV + VTV was commenced as per the no-recruitment maneuver (No-RM) group $(7,27)$.

\section{General Management after Birth}

Lambs were ventilated for 90 minutes, with poractant alfa $200 \mathrm{mg} / \mathrm{kg}$ (Chiesi Farmaceutici SpA) administered at 10 minutes, and $\mathrm{FI}_{\mathrm{O}_{2}}$ and VTV titrated to maintain an oxygen saturation as measured by pulse oximetry of $88-94 \%$ and a $\mathrm{Pa}_{\mathrm{CO}_{2}}$ of 40-60 $\mathrm{mm} \mathrm{Hg}$ after the first arterial gas measurement. At 90 minutes, a lethal dose of pentobarbitone was administered and a static in vivo pressure-volume curve generated from atmosphere to $35 \mathrm{~cm} \mathrm{H}_{2} \mathrm{O}$ (7, 8, 14, 18, 27). An additional 16 (8/season) gestation-matched lambs were killed at delivery as unventilated controls (UVC) for injury analysis comparison.

\section{Data Acquisition and Analysis}

Physiological, Cdyn, and ventilation parameters were recorded (LabChart; AD Instruments) and analyzed at key time points along with EIT data (8). Timecourse EIT image data were reconstructed using an anatomically correct, custom-built lamb algorithm $(30,31)$ filtered to the respiratory domain (IBEX software package; Swisstom) (27-29). Change in end-expiratory volume $(\triangle \mathrm{EEV})$ and VT were calculated from the trough and amplitude of the tidal timecourse EIT signal, respectively $(7,18)$. Within all the included lung regions (termed "global" signal), $\triangle \mathrm{EEV}$ from the preaerated state was calibrated from the static pressure-volume curve. Relative $\Delta \mathrm{EEV}$ within the gravity-dependent and nondependent regions was determined from the raw data and weighted to the known pixel contribution of each region $(18,27)$. The ventral-dorsal center of ventilation $(\mathrm{CoV})$ was used to define the spatiotemporal distribution of $\mathrm{VT}_{\mathrm{T}}(30)$. Representative functional images of ventilation are provided in Figure E1 in the online supplement.

\section{Lung Injury Analysis}

Immediately after animals were killed, the lungs were removed en bloc. Protein concentration of left lung BAL fluid was determined using the Lowry and colleagues method (32). The right upper lobe was inflation fixed at $20 \mathrm{~cm} \mathrm{H}_{2} \mathrm{O}$ with $4 \%$ paraformaldehyde and hematoxylin and eosin-stained, and five standardized sections from each of the dependent and nondependent zones assessed using standardized criteria $(8,18,33)$. Lung tissue samples were collected from the gravitydependent and nondependent zones of the right lower lobe and mRNA expression of six early biomarkers of lung injury determined using the $2^{-\Delta \Delta \mathrm{Ct}}$ method, as previously described (34).

\section{Statistical Analysis}

Based on our previous studies, 20-26 lambs/group were bred to allow comparison of regional injury expression between groups and lung regions (power $=0.8$; $\alpha$ error $=0.05)(7)$. After normality testing, data were analyzed with appropriate parametric or nonparametric tests (PRISM 6; GraphPad Software Inc.). A $P$ value less than 0.05 was considered significant.

\section{Results}

A total of 87 lambs was studied and included in the analysis. The groups were well matched other than fewer singletons in the DynPEEP group (Table 1). One ewe (twin; No-RM and DynPEEP) had a period of hypoxia during anesthetic induction, but fetal blood gas analysis was normal at delivery. Three lambs (one per intervention group) developed a pneumothorax during the super-syringe pressure-volume procedure at $35 \mathrm{~cm} \mathrm{H}_{2} \mathrm{O}$. The mean (SD) maximum PEEP was 17.9 (2.9) $\mathrm{cm} \mathrm{H}_{2} \mathrm{O}$ during the DynPEEP measurement.

\section{Gas Exchange, End-Expiratory Volume, Lung Mechanics, and Ventilator Parameters}

Overall, there was no difference in alveolar-arterial difference in oxygen (Figure 1A; $P=0.39$, repeated-measures ANOVA), but both time $(P<0.0001)$ and the use of DynPEEP $(P=0.008)$ significantly improved oxygenation. There was no difference in global $\triangle \mathrm{EEV}$ between the groups (Figure 1B), with all groups demonstrating an increase in EEV between
5 and 30 minutes (all $P<0.005$; one-way ANOVA with Tukey post hoc test). Cdyn was significantly higher after surfactant in the DynPEEP group compared with the SI and No-RM groups $(P<0.0001$;

Figure 1C), despite Cdyn being lower at birth and thus before the recruitment maneuver in this group. Correspondingly, PIP - PEEP at 90 minutes of life was $7 \mathrm{~cm}$ $\mathrm{H}_{2} \mathrm{O}$ and $3 \mathrm{~cm} \mathrm{H} \mathrm{H}_{2} \mathrm{O}$ less than the $\mathrm{SI}$ and No-RM groups (Figure 1D; $P<0.0001$ ). Delivered VT during the first 5 minutes was lower in the DynPEEP group than in the SI and No-RM groups (Figure 1E; $P=0.029$ ), with no differences thereafter. $\mathrm{Pa}_{\mathrm{CO}_{2}}$ was similar for all groups (Figure $1 \mathrm{~F}$ ).

\section{Spatiotemporal Aeration and Ventilation}

Figure 2 shows the gravity-dependent spatiotemporal pattern of relative aeration and ventilation during the study. There was no change in relative aeration over time in the no-RM group, which approached uniformity throughout the study (Figure 2A). Immediately after the DynPEEP maneuver (5 min of life), aeration was preferentially distributed toward the dependent lung, becoming more uniform with time $(P=0.0019$; paired Student's $t$ test). The SI resulted in significantly greater relative aeration in the nondependent lung than in the dependent lung. Unlike the other groups, in the SI group, this heterogeneity of aeration increased with time $(P=0.006)$, and exhibited more intersubject variability at each time point.

At 5 minutes, there was no difference in the gravity-dependent distribution of $\mathrm{VT}$, with all groups demonstrating preferential ventilation toward the nondependent lung (Figure 2B). By 90 minutes, Vт had become more uniform in the No-RM and DynPEEP groups. VT remained relatively greater in the nondependent lung in the SI group (Figure $\mathrm{E} 1$ ). $\mathrm{CoV}$ in the SI group was a mean (95\% confidence interval) of 1.6 (0.07-2.24)\% (No-RM) and 2.42 (1.48-3.36)\% (DynPEEP) further from the value representing uniform ventilation at 90 minutes (CoV of 59\%; paired Student's $t$ test).

The proportion of lung regions without any tidal ventilation (all located in peripheral/distal lung) was greater in the SI group at 5 minutes than at 90 minutes (Figure 2C; mean difference $=1.4$ $[0.2-2.6] \%)$. There was no difference in the 
Table 1. Subject Characteristics

\begin{tabular}{|c|c|c|c|c|c|c|c|c|c|c|}
\hline \multirow[b]{2}{*}{ Characteristics } & \multirow[b]{2}{*}{$n$} & \multirow[b]{2}{*}{$\begin{array}{c}\text { Birth } \\
\text { Weight }(k g)\end{array}$} & \multirow[b]{2}{*}{ Plurality (S:T) } & \multirow[b]{2}{*}{$\operatorname{Sex}(F: M)$} & \multirow[b]{2}{*}{$\begin{array}{c}\text { Lung Fluid } \\
\text { Drained }(\boldsymbol{m l} / \mathrm{kg})\end{array}$} & \multirow[b]{2}{*}{$\begin{array}{c}\text { 90-min Static } \\
\text { Crs }\left(\mathrm{ml} / \mathrm{kg} / \mathrm{cm} \mathrm{H}_{2} \mathrm{O}\right)\end{array}$} & \multicolumn{2}{|c|}{$\begin{array}{l}\text { Umbilical Cord Gas } \\
\text { Analysis }\end{array}$} & \multicolumn{2}{|c|}{$\begin{array}{c}\text { 90-Min Arterial Gas } \\
\text { Analysis }\end{array}$} \\
\hline & & & & & & & pH & $\begin{array}{c}\mathrm{Pa}_{\mathrm{O}_{2}} \\
(\mathrm{~mm} \mathrm{Hg})\end{array}$ & pH & $\begin{array}{c}\mathrm{Pa}_{\mathrm{O}_{2}} \\
(\mathrm{~mm} \mathrm{Hg})\end{array}$ \\
\hline $\begin{array}{l}\text { No-RM } \\
\text { SI } \\
\text { DynPEEP } \\
\text { UVC }\end{array}$ & $\begin{array}{l}19 \\
26 \\
26 \\
16\end{array}$ & $\begin{array}{l}3.31(0.48) \\
3.28(0.52) \\
3.36(0.40) \\
3.65(0.26)\end{array}$ & $\begin{array}{l}3: 16 \\
8: 19 \\
1: 25^{\dagger} \\
2: 14\end{array}$ & $\begin{array}{c}11: 8 \\
7: 19^{*} \\
14: 12 \\
9: 7\end{array}$ & $\begin{array}{c}17.8(7.1) \\
16.1(6.4) \\
16.7(3.8) \\
\text { N/A }\end{array}$ & $\begin{array}{c}1.31(0.23) \\
1.21(0.25) \\
1.24(0.17) \\
\text { N/A }\end{array}$ & $\begin{array}{l}7.33(0.05) \\
7.36(0.06) \\
7.37(0.07) \\
7.32(0.06)\end{array}$ & $\begin{array}{l}27.0(9.4) \\
26.9(5.5) \\
26.8(3.1) \\
22.5(4.8)\end{array}$ & $\begin{array}{c}7.27(0.09) \\
7.24(0.08) \\
7.24(0.05) \\
\text { N/A }\end{array}$ & $\begin{array}{c}47.4(11.3) \\
48.5(9.5) \\
46.1(6.3) \\
\text { N/A }\end{array}$ \\
\hline
\end{tabular}

Definition of abbreviations: $\mathrm{Crs}=$ static respiratory system compliance (terminal); DynPEEP = dynamic stepwise positive end-expiratory pressure; N/A = not applicable; No-RM = no-recruitment maneuver; $\mathrm{S}=$ singleton; $\mathrm{SI}=$ sustained inflation; $\mathrm{T}$ = twin/triplet; UVC = unventilated control.

All data are shown as mean $(\mathrm{SD})$ or ratios. Gestational age, $125( \pm 1)$ days.

${ }^{\star} P=0.06$ versus other groups (chi-square).

${ }^{\dagger} P<0.001$ versus other groups (chi-square).

no-RM and DynPEEP groups at 5 and 90 minutes.

\section{Molecular Pattern of Regional Injury}

In the nondependent lung (Figure 3), all three interventional groups demonstrated greater expression of the six gene markers of early lung injury initiation at 90 minutes when compared with the UVC group (all
$P<0.05$; Kruskal-Wallis test with Dunn's post hoc test). CTGF and EGR1 expression was also lower in the DynPEEP group compared with the SI and No-RM groups. In the dependent lung, only the SI group had significantly greater relative gene expression than UVC, except for IL-8 expression in the DynPEEP group (Figure 4).

\section{Lung Histology}

There was no difference in the regional pattern of total airway space or alveolar wall thickness at 90 minutes between the three intervention groups (Figures 5A and 5B). Alveolar area was similar within each region for the UVC, SI, and DynPEEP groups, and in each case less than for NoRM (Figure 5C; $P=0.0011$; [nondependent]
A

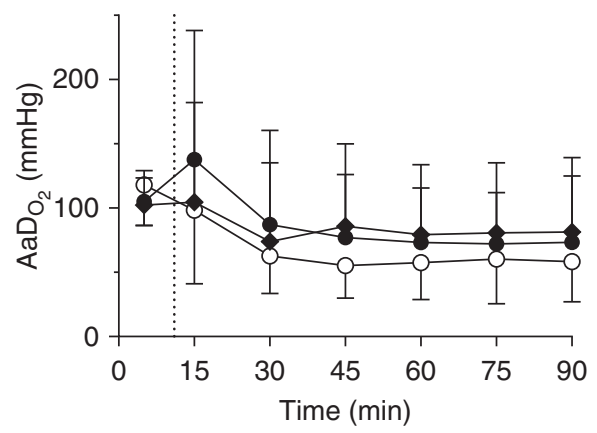

D

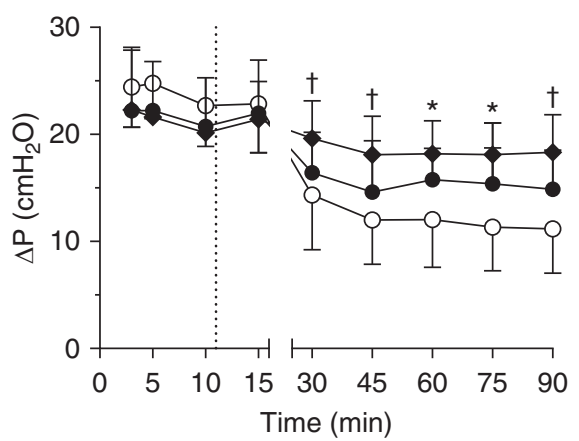

B

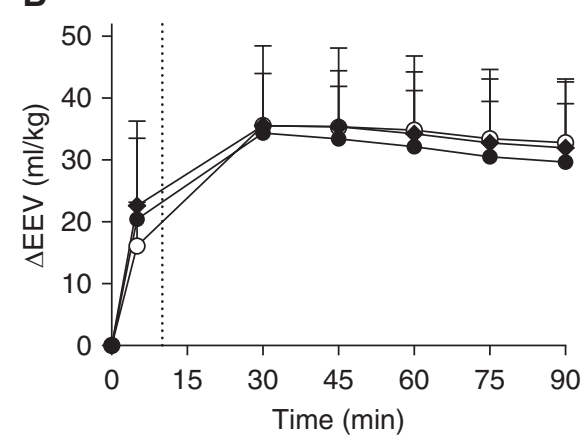

E

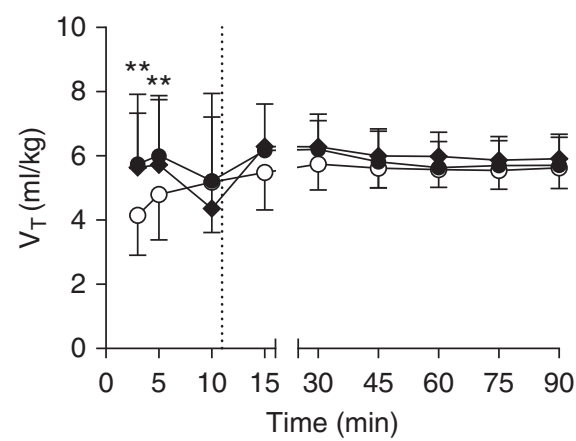

C

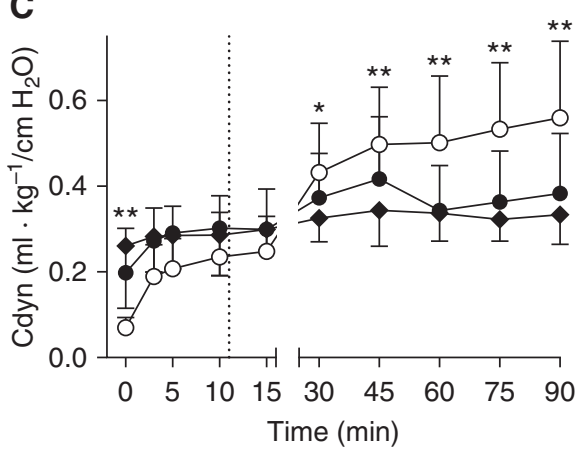

$\mathbf{F}$

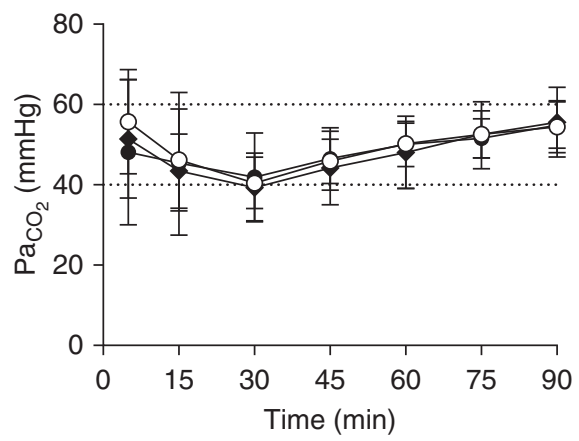

Figure 1. (A) Alveolar-arterial difference in oxygen $\left(\mathrm{AaD}_{\mathrm{O}_{2}}\right),(B)$ global change in end-expiratory volume from preaeration state (change in end-expiratory volume $[\Delta \mathrm{EEV}]),(C)$ dynamic compliance $(\mathrm{Cdyn}),(D)$ pressure amplitude (peak inspiratory pressure - positive end-expiratory pressure $[\Delta \mathrm{P}]),(E) \mathrm{V}_{\mathrm{T}}$, and $(F)$ $\mathrm{Pa}_{\mathrm{CO}_{2}}$ after the no-recruitment maneuver (No-RM; solid circles), dynamic stepwise positive end-expiratory pressure (DynPEEP) (open circles), and sustained inflation (SI; solid diamonds) strategies. $(A-E)$ Dotted vertical line: timing of exogenous surfactant administration. $(F)$ Horizontal dotted lines: target $\mathrm{PaCO}_{2}$ range. Intergroup differences: all $P<0.05$ (two-way repeated measures ANOVA with Tukey post hoc tests); ${ }^{*} \mathrm{SI}$ versus DynPEEP, ${ }^{* *} \mathrm{SI}$ and No-RM versus DynPEEP (including at time point 0 min in $C$ ), and ${ }^{\dagger}$ SI versus DynPEEP and No-RM. All data are presented as mean \pm SD. 
A

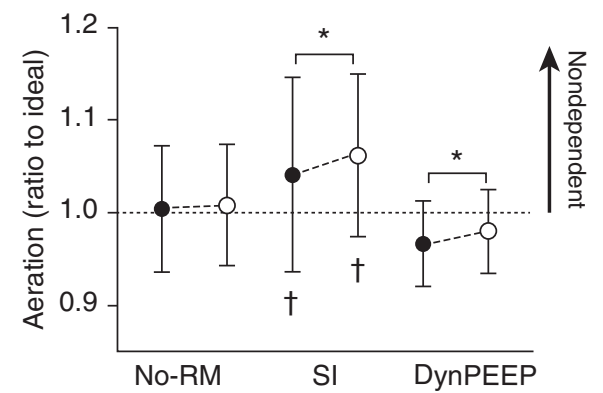

B

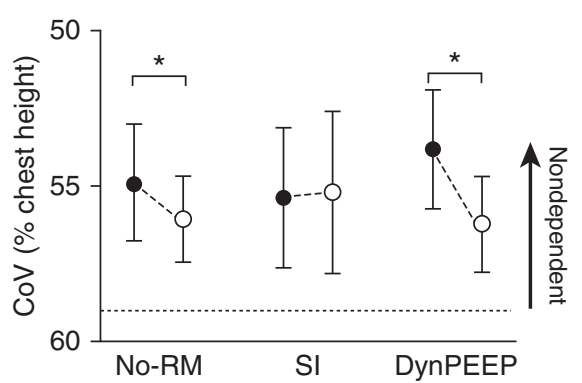

C

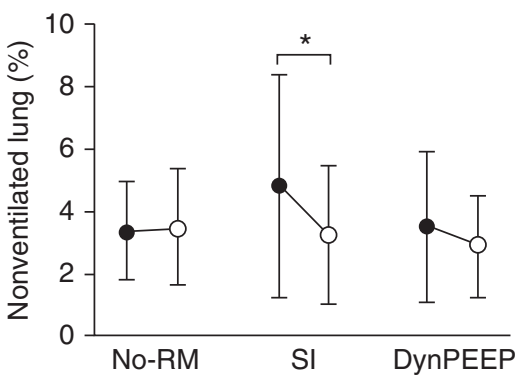

Figure 2. (A) Relative distribution of aeration at 5 minutes (solid circles) and 90 minutes (open circles) of life expressed as the ratio of measured aeration to ideal aeration distribution within the lung. A value of 1.0 indicates that aeration is distributed evenly throughout the lung after accounting for the anatomic shape of the lungs within the image slice. A value greater than 1.0 indicates relatively greater aeration in the nondependent lung $(27,30)$. (B) Center of ventilation (CoV) within the ventral-dorsal plane (same time points and symbols as in $A$ ), expressed as a percentage of chest height from most nondependent $(0 \%)$ to most dependent (100\%) regions of the chest (29). Anatomically uniform CoV for tidal ventilation occurs at $59 \%$ (dashed horizontal line), with values less than 59\% representing $V_{T}$ preferentially distributed toward the nondependent lung (8). (C) Proportion of lung without any apparent $V_{T}$ at the same time points and symbols as in $A .{ }^{*}$ Values differ between 5 and 90 minutes $\left(P<0.05\right.$, paired Student's $t$ tests); ${ }^{\dagger}$ sustained inflation (SI) and dynamic stepwise positive end-expiratory pressure (DynPEEP) groups differ at same time point $(P<0.05$, one-way ANOVA). All data are presented as mean $\pm \mathrm{SD}$. No-RM = no-recruitment maneuver.

and $P=0.0005$ [dependent], one-way ANOVA). All three interventional groups had a greater number of detached epithelial cells in the nondependent lung than in the dependent lung (Figure 5D; all $P<0.05$, paired Student's $t$ test). Within the nondependent lung, the SI group had more detached epithelial cells than the other groups $(P=0.0003$, one-way ANOVA). There was no difference in the dependent lung $(P=0.063)$. Left lung lavage fluid protein was not different between the groups and UVC $(P=0.34$, one-way ANOVA; Figure E2).

\section{Discussion}

This is the first study that defines the regional spatiotemporal volume-injury interactions in the preterm lung after initiation of respiratory support at birth. We identified significant regional differences in lung injury after the use of an SI compared with PEEP-supported tidal ventilation in our steroid-exposed and surfactant-treated apneic preterm lambs. Although all respiratory strategies initiated similar injury in the nondependent lung, an SI generated greater expression of early injury markers in the gravity-dependent
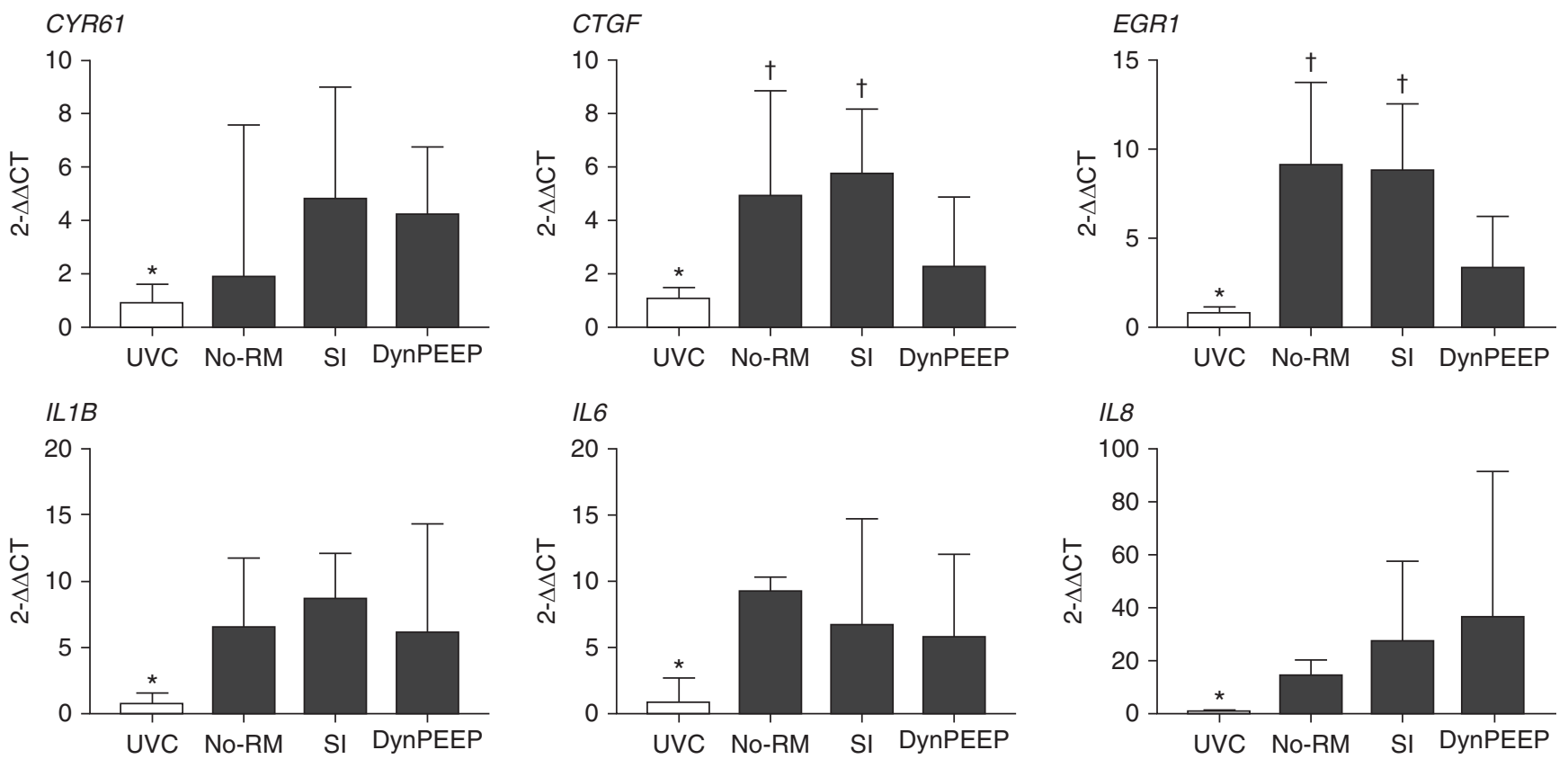

Figure 3. Relative gene expression of CYR61, CTGF, EGR1, IL-1B, IL-6, and IL-8 at 90 minutes of life in the non-gravity-dependent hemithorax for the three interventional strategies and an unventilated fetal control (UVC) group. Intergroup differences: $P<0.05$, Kruskal-Wallis test with Dunn's post hoc tests: *UVC versus the three intervention groups and ${ }^{\dagger}$ sustained inflation (SI) and no-recruitment maneuver (No-RM) versus the other two groups. All data are presented as median + interquartile range. DynPEEP = dynamic stepwise positive end-expiratory pressure. 

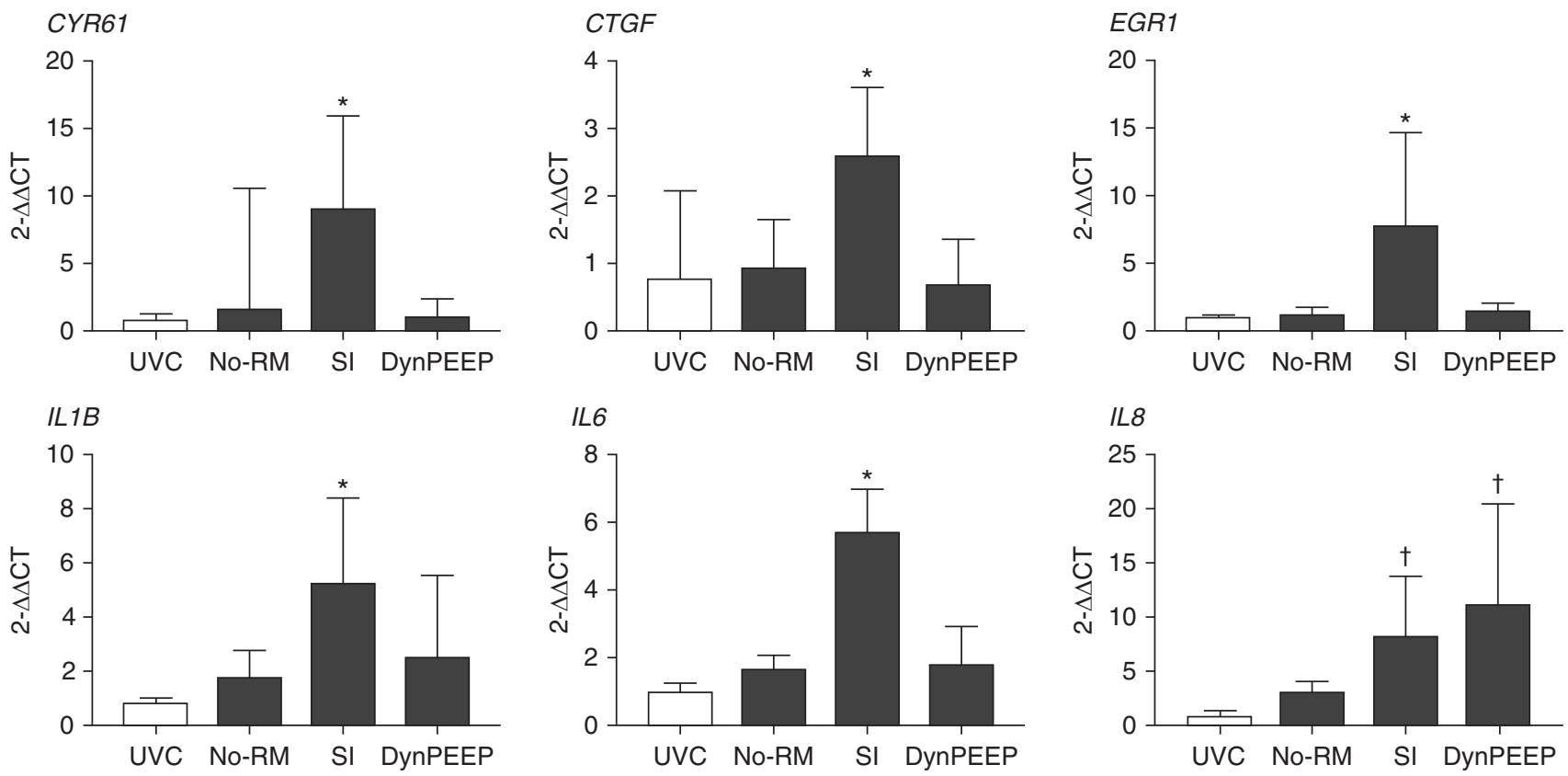

Figure 4. Relative gene expression of CYR61, CTGF, EGR1, IL-1B, IL-6, and IL-8 at 90 minutes of life in the gravity-dependent hemithorax for the three interventional strategies and an unventilated fetal control group (UVC). Intergroup differences: $P<0.05$, Kruskal-Wallis test with Dunn's post hoc tests: *sustained inflation (SI) versus UVC, dynamic stepwise positive end-expiratory pressure (DynPEEP), and no-recruitment maneuver (No-RM), and ${ }^{\dagger} S I$ and DynPEEP versus UVC. All data are presented as median + interquartile range.

lung regions by 90 minutes of life. Importantly, these injury events were explained by the spatiotemporal differences in regional aeration and ventilation induced by each recruitment strategy. Specifically, rapidly aerating the developmentally immature preterm lung with an SI does not generate uniform aeration. This evolved with, and impacted, continuing PPV, and, by study conclusion, produced regionally distinct injury events. Our study demonstrates that application of sufficient PEEP is the most important, effective, and safe way to facilitate respiratory transition at birth.

Enthusiasm for an SI as a method of assisting respiratory transition in the preterm newborn has been stimulated by: 1) the appreciation that healthy term infants transition with the aid of deep and prolonged inspirations and high intrathoracic pressures (4-6), coupled with 2) phase-contrast imaging data from rabbit pups demonstrating more rapid airway fluid clearance with an SI than with PPV alone $(12,13)$. Importantly, these imaging studies were not designed to examine volume-injury interactions. Our study, in a different species in which lung fluid was partially cleared by passive drainage, and in which antenatal corticosteroids and exogenous surfactant were given, did not find a functional benefit of SI. The longer study duration also allowed the regional volume-injury interactions to unfold. Despite an attempt to minimize inadequate aeration or excessive pressure exposure by individualizing the SI duration to the mechanical state of the lung $(7,18,27)$, aeration and ventilation responses were most variable and also least uniform using an SI. This conferred no clinical benefit over PPV with PEEP from birth, despite the DynPEEP group having worse lung mechanics at birth. The canalicular/ saccular developmental state of the preterm lung is not prepared for aeration, and emulating the rapid aeration process that occurs in the alveolarized term lung exposes the lung to pressure and volume conditions that initiate injury. This suggests that focusing on rapid and complete lung aeration as the first priority at birth causes unintentional harm. We contend that the developmental differences in lung morphology between the extremely preterm lung and the healthy term lung, combined with greater regional variability in time constants within the surfactant-deficient preterm lung, necessitate a different approach to facilitate aeration at birth.
To our knowledge, this study is the first designed and powered to evaluate the manifestations of regional lung injury during the respiratory transition immediately after birth. Crucially, all strategies initiated injury in the nondependent lung, highlighting that some form of injury is inevitable after positive pressure support to the apneic preterm lung. The non-gravity-dependent lung regions are preferentially ventilated in the surfactant-deficient lung at birth, and thus likely to receive most of any delivered volume during the initial respiratory transition, with the potential for inadvertent overdistension (2). It has previously been proposed that ventilation should commence with a small $\mathrm{VT}$, which is then gradually increased as aeration progresses through the lung, to avoid volutrauma (2). Interestingly, DynPEEP, which used lower $\mathrm{V}_{\mathrm{T}}$ during the escalating PEEP phase, was the only strategy with relative aeration favoring the dependent lung at 5 minutes of life. DynPEEP also had the best Cdyn, oxygenation, surfactant response, and, subsequently, lower PIP needs, as well as the lowest expression of EGR1 and CTGF in the nondependent lung. The benefits of a DynPEEP approach at birth may be due to the dual effect of 
A

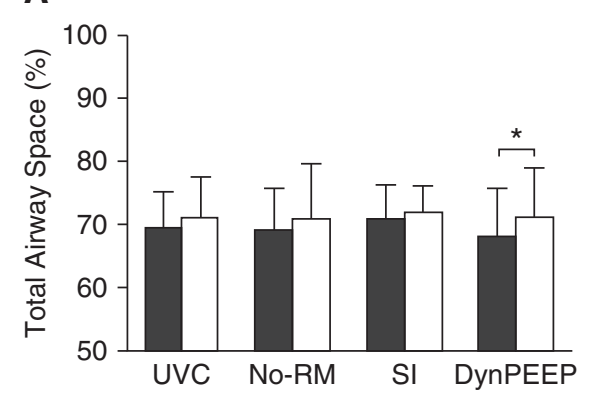

C

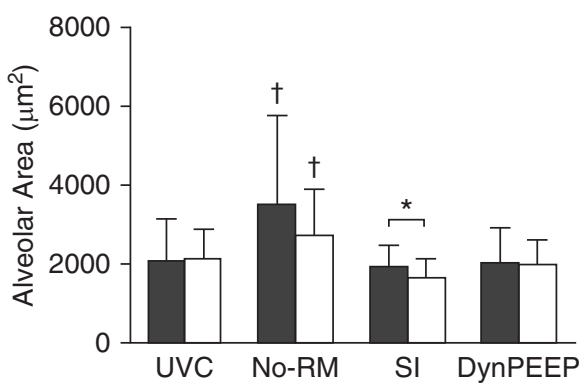

B

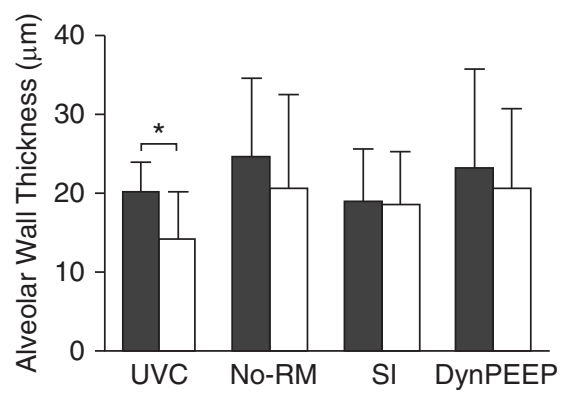

D

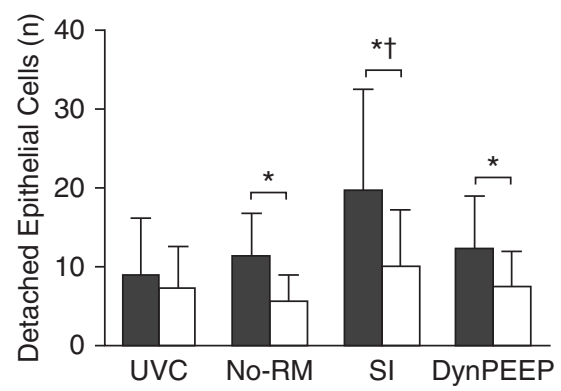

Figure 5. Histological injury assessment at 90 minutes of life in the nondependent (solid bars) and dependent (open bars) hemithoraces for the no-recruitment maneuver (No-RM), sustained inflation (SI), and dynamic stepwise positive end-expiratory pressure (DynPEEP) strategies, and unventilated fetal controls (UVCs). (A) Total airway space, $(B)$ alveolar wall thickness, $(C)$ alveolar area, and $(D)$ detached epithelial cells (number per high power field). Intergroup differences: *difference between dependent and nondependent regions within a strategy $(P<0.05$, paired Student's $t$ tests), and ${ }^{\dagger}$ a difference between that strategy and all other strategies, including UVC $(P<0.05$, one-way ANOVA with Tukey post hoc tests). All bars are presented as mean + SD.

PEEP-mediated aeration $(16,35)$ and lower VT delivery related to reduced PIP - PEEP during the PEEP escalation phase. Our findings add increasing weight to the need for clinical investigation of PEEP levels in the delivery room, specifically the use of a dynamic PEEP approach targeting an initial high PEEP to facilitate aeration $(1,8,16)$.

Although clinical studies have shown promising short-term outcomes from an SI (35), the recent finding of higher early mortality after an SI in the SAIL (Sustained Aeration of Infants Lungs) Trial $(37,38)$ has raised concern that an SI may have an injury-provoking effect. Björklund and coworkers $(19,20)$ found that widespread lung injury could be initiated in preterm lambs after a single large SI at birth intentionally designed to initiate volutrauma. Even with an SI designed to minimize inadvertent exposure to high volumes, greater injury occurs compared with tidal ventilation. Our use of EIT demonstrated that an SI created a more heterogeneous, and less predictable, aeration pattern in the lung, with concomitant dependent lung atelectasis and nondependent lung overdistension, respectively. Previous studies of regional aeration patterns after an SI have used rabbit pups under $40 \mathrm{~g}$, in which size limits the exhibition of gravity-dependent aeration differences $(13,39)$. The heterogeneity of aeration and ventilation after an SI was not only gravity dependent, but also associated with less peripheral lung ventilation. We propose that an SI preferentially aerates regions with better mechanics (the nondependent lung and regions closer to major airways), potentiating injury within these regions because of the continuous stretch associated with the long exposure to a high distending pressure. The failure to aerate less compliant (dependent) regions results in atelectasis. More worryingly, the lack of temporal improvement in dependent lung ventilation in the SI group, and impaired Cdyn response to surfactant, indicates that the heterogeneous injury response likely increases with time. This sequence of events may provide a rationale for the early adverse outcomes observed after an SI in the SAIL Trial.

Irrespective of how aeration is achieved, respiratory transition extends beyond the first few inflations, and is always via tidal ventilation (1). Our study adds considerable weight to the argument that focusing on the ongoing process of supporting ventilation during the respiratory transition is more important than the initial aeration events (7). Critical to the lung-protective benefits of PPVmediated aeration was the use of PEEP to prevent aeration loss via intra-alveolar fluid influx during expiration. Most preterm infants attempt to breathe after birth (40), but periods of glottic closure are common, and may impede pressure delivery (1). As PEEP can be applied over long periods during spontaneous and positive-pressure inflations, and during noninvasive and intubated support, it has practical advantages over a single SI. Both our strategies used PEEP values that would be considered high compared with other preterm lamb studies $(9,10,12,13,17)$, but have previously been shown to be optimal $(16,41)$. Based on our recent work (7), the lack of injury difference between the No-RM and DynPEEP groups was surprising. Unlike our previous studies, we used steroid-exposed and surfactanttreated lambs, which more closely reflects clinical practice. Our study adds further experimental evidence to support PEEP as the most important respiratory support parameter in the delivery room (10), despite a lack of robust clinical data.

\section{Limitations}

The limitations of EIT are well described (30). EIT is currently the only method of assessing regional ventilation and aeration patterns easily and repeatedly over long periods of time, but is limited to a single cross-sectional plane that is changing (30). The use of a reconstruction algorithm reduces, but does not totally ameliorate, shape deformation (30). In mechanically ventilated neonates, assessment of crosssectional change in lung volume measured with EIT has been shown to be representative of whole-lung volume (42). The use of anatomically correct image reconstruction algorithms reduces, but does not completely ameliorate, the chance of measuring non-lung tissue $(30,31)$. We limited our assessment of lung injury to the 
events initiating injury, and used previously reported molecular and histological measures $(24,34,43)$, albeit assessed in different lobes of the right lung, limiting comparison. These measures cannot be assumed to predict later chronic lung disease outcomes, and the a priori choice of measures may have missed other injury pathways. Our study was comparable with others in this field $(10,17,43)$, in that the lambs were anesthetized, intubated, and managed with a cuffed endotracheal tube to ensure accuracy of measurements, inconsistent with clinical practice. It is likely that different aeration and ventilation patterns would occur during facemask support during spontaneous breathing. The absolute pressure and volume settings used in this study were based on values found to be optimal in our previous preterm lamb studies $(7,8,11$, 16), but should not be directly translated to the preterm human infant. Human infants are likely to need lower PEEP, VT, SI duration, and inflating pressures.

\section{Conclusions}

Irrespective of strategy, PPV from birth initiates nondependent lung injury in the preterm lamb. In contrast to tidal ventilation, especially combined with dynamic PEEP, the use of an SI generates the least-uniform lung aeration, causing complex early regional injury patterns that are potentiated by ongoing PPV. Our study challenges the emphasis on rapid lung aeration at birth, suggesting that any short-term gains translate into long-term risk, and that achieving aeration gradually may be safer. PEEP remains the most important parameter for supporting the preterm lung at birth, and supporting tidal ventilation using adequate PEEP is the most effective method of achieving aeration while maximizing lung protection at birth.

Author disclosures are available with the text of this article at www.atsjournals.org.

Acknowledgment: The authors acknowledge Dr. Anushi Rajapaksa for assistance in lamb management and preparation of gas exchange and mechanics data, Sarah White and Rebecca Sutton for assistance in preparation of the ewes, and Georgie Dowse for assistance in electrical impedance tomography analysis.

\section{References}

1. Hooper SB, Te Pas AB, Kitchen MJ. Respiratory transition in the newborn: a three-phase process. Arch Dis Child Fetal Neonatal Ed 2016;101:F266-F271.

2. Jobe AH, Hillman N, Polglase G, Kramer BW, Kallapur S, Pillow J. Injury and inflammation from resuscitation of the preterm infant. Neonatology 2008;94:190-196.

3. Hooper SB, Kitchen MJ, Wallace MJ, Yagi N, Uesugi K, Morgan MJ, et al. Imaging lung aeration and lung liquid clearance at birth. FASEB $J$ 2007;21:3329-3337.

4. Milner AD, Vyas H. Lung expansion at birth. J Pediatr 1982;101:879-886.

5. Vyas $H$, Milner AD, Hopkins IE. Intrathoracic pressure and volume changes during the spontaneous onset of respiration in babies born by cesarean section and by vaginal delivery. J Pediatr 1981;99: 787-791.

6. Boon AW, Milner AD, Hopkin IE. Lung expansion, tidal exchange, and formation of the functional residual capacity during resuscitation of asphyxiated neonates. J Pediatr 1979;95:1031-1036.

7. Tingay DG, Rajapaksa A, Zannin E, Pereira-Fantini PM, Dellaca RL, Perkins EJ, et al. Effectiveness of individualized lung recruitment strategies at birth: an experimental study in preterm lambs. $A m \mathrm{~J}$ Physiol Lung Cell Mol Physiol 2017;312:L32-L41.

8. Tingay DG, Rajapaksa A, Zonneveld CE, Black D, Perkins EJ, Adler A, et al. Spatiotemporal aeration and lung injury patterns are influenced by the first inflation strategy at birth. Am J Respir Cell Mol Biol 2016; 54:263-272.

9. Hillman NH, Kemp MW, Noble PB, Kallapur SG, Jobe AH. Sustained inflation at birth did not protect preterm fetal sheep from lung injury. Am J Physiol Lung Cell Mol Physiol 2013;305:L446-L453.

10. Hillman NH, Nitsos I, Berry C, Pillow JJ, Kallapur SG, Jobe AH. Positive end-expiratory pressure and surfactant decrease lung injury during initiation of ventilation in fetal sheep. Am J Physiol Lung Cell Mol Physiol 2011;301:L712-L720.

11. McCall KE, Davis PG, Owen LS, Tingay DG. Sustained lung inflation at birth: what do we know, and what do we need to know? Arch Dis Child Fetal Neonatal Ed 2016;101:F175-F180.

12. te Pas AB, Siew M, Wallace MJ, Kitchen MJ, Fouras A, Lewis RA, et al. Effect of sustained inflation length on establishing functional residual capacity at birth in ventilated premature rabbits. Pediatr Res 2009; 66:295-300.

13. te Pas AB, Siew M, Wallace MJ, Kitchen MJ, Fouras A, Lewis RA, et al. Establishing functional residual capacity at birth: the effect of sustained inflation and positive end-expiratory pressure in a preterm rabbit model. Pediatr Res 2009;65:537-541.
14. Tingay DG, Polglase GR, Bhatia R, Berry CA, Kopotic RJ, Kopotic CP, et al. Pressure-limited sustained inflation vs. gradual tidal inflations for resuscitation in preterm lambs. J Appl Physiol (1985) 2015;118: 890-897.

15. Polglase GR, Tingay DG, Bhatia R, Berry CA, Kopotic RJ, Kopotic CP, et al. Pressure- versus volume-limited sustained inflations at resuscitation of premature newborn lambs. BMC Pediatr 2014;14:43.

16. Tingay DG, Bhatia R, Schmölzer GM, Wallace MJ, Zahra VA, Davis PG. Effect of sustained inflation vs. stepwise PEEP strategy at birth on gas exchange and lung mechanics in preterm lambs. Pediatr Res 2014;75:288-294.

17. Sobotka KS, Hooper SB, Allison BJ, Te Pas AB, Davis PG, Morley CJ, et al. An initial sustained inflation improves the respiratory and cardiovascular transition at birth in preterm lambs. Pediatr Res 2011; 70:56-60.

18. Tingay DG, Lavizzari A, Zonneveld CE, Rajapaksa A, Zannin E, Perkins $\mathrm{E}$, et al. An individualized approach to sustained inflation duration at birth improves outcomes in newborn preterm lambs. Am J Physiol Lung Cell Mol Physiol 2015;309:L1138-L1149.

19. Björklund LJ, Ingimarsson J, Curstedt T, Larsson A, Robertson B, Werner $O$. Lung recruitment at birth does not improve lung function in immature lambs receiving surfactant. Acta Anaesthesiol Scand 2001;45:986-993.

20. Björklund LJ, Ingimarsson J, Curstedt T, John J, Robertson B, Werner $\mathrm{O}$, et al. Manual ventilation with a few large breaths at birth compromises the therapeutic effect of subsequent surfactant replacement in immature lambs. Pediatr Res 1997;42:348-355.

21. Steinberg JM, Schiller HJ, Halter JM, Gatto LA, Lee HM, Pavone LA, et al. Alveolar instability causes early ventilator-induced lung injury independent of neutrophils. Am J Respir Crit Care Med 2004;169: 57-63.

22. Schiller HJ, Steinberg J, Halter J, McCann U, DaSilva M, Gatto LA, et al. Alveolar inflation during generation of a quasi-static pressure/volume curve in the acutely injured lung. Crit Care Med 2003;31:1126-1133.

23. Crotti S, Mascheroni D, Caironi P, Pelosi P, Ronzoni G, Mondino M, et al. Recruitment and derecruitment during acute respiratory failure: a clinical study. Am J Respir Crit Care Med 2001;164:131-140.

24. Wallace MJ, Probyn ME, Zahra VA, Crossley K, Cole TJ, Davis PG, et al. Early biomarkers and potential mediators of ventilation-induced lung injury in very preterm lambs. Respir Res 2009;10:19.

25. Tingay DG, Pereira-Fantini PM, Oakley R, McCall KE, Perkins EJ, Miedema M, et al. Sustained inflation increases expression of early injury markers in the dependent lung of the steroid-exposed, surfactant-treated preterm lamb [abstract]. Presented at the PAS 
Pediatric Academic Society Annual Scientific Meeting. May 6-9, 2017, San Francisco, CA. Abstract 4455.3.

26. Tingay DG, Togo A, Pereira-Fantini PM, Miedema M, McCall KE, Perkins EJ, et al. Aeration strategy at birth influences the physiological response to surfactant in preterm lambs. Arch Dis Child Fetal Neonatal Ed [online ahead of print] 1 Feb 2019; DOI: 10.1136.archdischild-2018-316240.

27. McCall KE, Waldmann AD, Pereira-Fantini P, Oakley R, Miedema M, Perkins EJ, et al. Time to lung aeration during a sustained inflation at birth is influenced by gestation in lambs. Pediatr Res 2017;82: 712-720.

28. Miedema M, McCall KE, Perkins EJ, Sourial M, Böhm SH, Waldmann A, et al. First real-time visualization of a spontaneous pneumothorax developing in a preterm lamb using electrical impedance tomography. Am J Respir Crit Care Med 2016;194:116-118.

29. Miedema M, Waldmann A, McCall KE, Böhm SH, van Kaam AH, Tingay DG. Individualized multiplanar electrical impedance tomography in infants to optimize lung monitoring. Am J Respir Crit Care Med 2017; 195:536-538.

30. Frerichs I, Amato MB, van Kaam AH, Tingay DG, Zhao Z, Grychtol B, et al.; TREND Study Group. Chest electrical impedance tomography examination, data analysis, terminology, clinical use and recommendations: consensus statement of the TRanslational EIT developmeNt stuDy group. Thorax 2017;72: 83-93.

31. Adler A, Arnold JH, Bayford R, Borsic A, Brown B, Dixon P, et al. GREIT: a unified approach to 2D linear EIT reconstruction of lung images. Physiol Meas 2009;30:S35-S55.

32. Lowry OH, Rosebrough NJ, Farr AL, Randall RJ. Protein measurement with the Folin phenol reagent. $J$ Biol Chem 1951;193:265-275.

33. Schneider CA, Rasband WS, Eliceiri KW. NIH Image to ImageJ: 25 years of image analysis. Nat Methods 2012;9:671-675.

34. Pereira-Fantini PM, Rajapaksa AE, Oakley R, Tingay DG. Selection of reference genes for gene expression studies related to lung injury in a preterm lamb model. Sci Rep 2016;6:26476.
35. Tingay DG, Mills JF, Morley CJ, Pellicano A, Dargaville PA. The deflation limb of the pressure-volume relationship in infants during high-frequency ventilation. Am J Respir Crit Care Med 2006;173: 414-420.

36. Schmölzer GM, Kumar M, Aziz K, Pichler G, O’Reilly M, Lista G, et al. Sustained inflation versus positive pressure ventilation at birth: a systematic review and meta-analysis. Arch Dis Child Fetal Neonatal Ed 2015;100:F361-F368.

37. Kirpalani H, Ratcliffe SJ, Keszler M, Davis PG, Foglia EE, Te Pas A, et al. Effect of sustained inflations vs intermittent positive pressure ventilation on bronchopulmonary dysplasia or death among extremely preterm infants: the SAIL randomized clinical trial. JAMA 2019;321:1165-1175.

38. Foglia EE, Owen LS, Thio M, Ratcliffe SJ, Lista G, Te Pas A, et al. Sustained Aeration of Infant Lungs (SAIL) Trial: study protocol for a randomized controlled trial. Trials 2015;16:95.

39. Siew ML, Te Pas AB, Wallace MJ, Kitchen MJ, Lewis RA, Fouras A, et al. Positive end-expiratory pressure enhances development of a functional residual capacity in preterm rabbits ventilated from birth. J Appl Physiol (1985) 2009;106:1487-1493.

40. O'Donnell CP, Kamlin CO, Davis PG, Morley CJ. Crying and breathing by extremely preterm infants immediately after birth. J Pediatr 2010; 156:846-847.

41. Probyn ME, Hooper SB, Dargaville PA, McCallion N, Crossley K, Harding R, et al. Positive end expiratory pressure during resuscitation of premature lambs rapidly improves blood gases without adversely affecting arterial pressure. Pediatr Res 2004;56:198-204.

42. van der Burg PS, Miedema M, de Jongh FH, Frerichs I, van Kaam AH. Cross-sectional changes in lung volume measured by electrical impedance tomography are representative for the whole lung in ventilated preterm infants. Crit Care Med 2014;42:1524-1530.

43. Hillman NH, Moss TJ, Kallapur SG, Bachurski C, Pillow JJ, Polglase $\mathrm{GR}$, et al. Brief, large tidal volume ventilation initiates lung injury and a systemic response in fetal sheep. Am J Respir Crit Care Med 2007; 176:575-581. 
Reproduced with permission of copyright owner. Further reproduction prohibited without permission. 